\title{
Curative effect of laparoscopic hysterectomy for uterine fibroids and its impact on ovarian blood supply
}

\author{
XING WANG ${ }^{*}, \mathrm{LI} \mathrm{LV}^{*}$, ZHIYONG CHENG and XUEWU ZHOU \\ Department of Obstetrics and Gynecology, Daqing Longnan Hospital, The Fifth Hospital \\ of Qiqihar Medical University, Daqing, Heilongjiang 163453, P.R. China
}

Received June 14, 2017; Accepted August 7, 2017

DOI: $10.3892 /$ etm.2017.4944

\begin{abstract}
This study evaluates the curative effects laparoscopic hysterectomies performed to treat uterine fibroids and determined the impact of the procedures on ovarian blood supply. A total of 124 patients with uterine fibroids admitted and treated in our hospital from December 2014 to December 2015 participated in the study. Two groups of 62 patients each were formed according to different operating plans; one group of patients underwent abdominal (open) panhysterectomy and were set as the control group; with the other group of patients were treated with laparoscopic hysterectomy and were set as the observation group. Ovarian endocrine function tests and blood supply changes were measured in both groups before the operation and one month after it, and the clinical conditions of all the patients were followed up for 24 months after surgery. Our results showed the duration of operation, amount of bleeding and time to recovery after the procedure were significantly lower in the patients in the observation group $(\mathrm{P}<0.05)$. Also, compared with preoperative conditions, the levels of PRL, FSH, E2, LH and other ovarian function markers in both groups were significantly lower one month after the operation, but the levels of the patients in the observation group were still significantly higher than those of the patients in the control group $(\mathrm{P}<0.05)$. Likewise, the surgeries affected the ovarian blood supply in patients of both groups, as evidenced by the lower levels of PI, RI, Vmin, Vmax and other blood supply indexes observed by Doppler ultrasound a month after the operations. However, the impact of the surgery on the ovarian blood supply was less marked in the patients in the observation group as their levels remained higher than
\end{abstract}

Correspondence to: Dr Xuewu Zhou, Department of Obstetrics and Gynecology, Daqing Longnan Hospital, The Fifth Hospital of Qiqihar Medical University, 35 Aiguo Road, Daqing, Heilongjiang 163453, P.R. China

E-mail: zhouxw429@163.com

${ }^{*}$ Contributed equally

Key words: laparoscope, hysterectomy, uterine fibroids, ovarian blood supply those of patients in the control group $(\mathrm{P}<0.05)$. The numbers of patients with completely healed abdominal muscular layers in the observation group were always significantly higher than those of patients in the control group, at every different time point examined (1, 4, 8 and 12 months after surgery) $(\mathrm{P}<0.01)$. At the end of the 24 months of the follow-up period, the recurrence rate of fibroids for patients in the observation group was $4.8 \%$. In our hands, the laparoscopic hysterectomy procedure to treat uterine fibroids showed the usual advantages over the abdominal open hysterectomy, like small trauma, short surgical procedure and rapid postoperative recovery, but it also proved to cause a significantly smaller impact on ovarian blood supply and should be considered whenever uterus preservation is a priority.

\section{Introduction}

Uterine fibroids are common gynecological tumors, which have a complicated pathogenesis. Surgical removal is the most common approach to treating uterine fibroids (1). Given the reproductive and endocrine roles of the uterus, surgical modifications to the organ may affect its reproductive function and result in changes in the sex hormone levels released by the ovaries due to resulting changes in ovarian blood supply $(2,3)$. Therefore, the selection of the surgical method has an important impact on the outcomes for the patient and the evidence is not yet conclusive as to the best approach to treat uterine fibroids. This study analyzed and compared the results of the selected 124 cases with uterine fibroids who underwent either abdominal total or partial laparoscopic hysterectomy.

\section{Patients and methods}

General data. A total of 124 patients treated in Daqing Longnan Hospital from December 2014 to December 2015 were enrolled in the study. The patients' ages ranged from 22 to 56 years with an average of $33.28 \pm 4.63$. There were 82 women with multiple uterine fibroids and 42 with a single fibroid tumor. All patients received definite uterine fibroids diagnoses (with malignancies excluded) based on gynecological examinations and color doppler ultrasound imaging (4). All patients were married, and had no outstanding diseases or conditions affecting major organs. The patients were divided into two groups of 62 cases in each, according to the two 
Table I. Comparison of average surgical characteristics of patients in both groups (mean \pm SD).

\begin{tabular}{lcccc}
\hline Groups & $\mathrm{n}$ & $\begin{array}{c}\text { Duration of } \\
\text { operation (min) }\end{array}$ & $\begin{array}{c}\text { Amount of bleeding } \\
\text { during procedure (ml) }\end{array}$ & $\begin{array}{c}\text { Recovery } \\
\text { period (h) }\end{array}$ \\
\hline Control & 62 & $108.26 \pm 10.36$ & $136.28 \pm 11.30$ & $26.87 \pm 3.96$ \\
Observation & 62 & $97.63 \pm 5.36$ & $101.34 \pm 8.67$ & $22.14 \pm 3.82$ \\
t-test & & 6.783 & 7.651 & 8.004 \\
P-value & $<0.05$ & $<0.05$ & $<0.05$ \\
\hline
\end{tabular}

$\mathrm{SD}$, standard deviation.

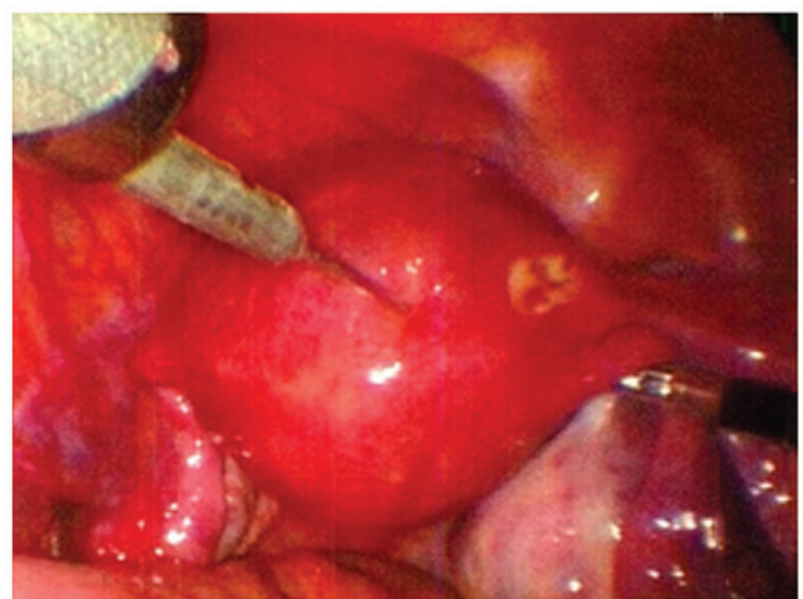

Figure 1. Photograph of general view of laparoscopic hysterectomy.

different operation plans adopted for the study. The general characteristics of the patients between the two groups did not differ significantly $(P>0.05)$. The Hospital Ethics Committee approved this study and patients signed informed consent forms.

Methods. In this study, the patients in the control group were treated with abdominal panhysterectomy. Continuous epidural anesthesia was provided and an incision was made in the hypogastric middle region. The ovarian inherent and round ligaments were successively dissected and cut-off. The lobus anterior of the broad ligament and the folded bladder peritoneum were opened. The uterine veins and arteries were dissected after separating the bladder. The vaginal wall was cut open annularly. After the uterus was taken out, the vaginal stub-end was sutured, returned and folded in place and then the abdomen was sutured closed plane by plane.

The patients in the observation group were treated with laparoscopic hysterectomy, under general anesthesia. The lithotomy position was chosen for the procedure and the perineum was disinfected. A drainage tube was imbedded within the urethra. After the urine was evacuated, a uterine manipulator was put in place. The uterine fibroids were removed through the pneumoperitoneum puncture. After that, the abdominal cavity was washed and the $\mathrm{CO}_{2}$ gas was extracted. Puncture holes were sutured completely under a laparoscope. See Fig. 1 for laparoscopic view and Fig. 2 for pathology slide example from the removed tissues.

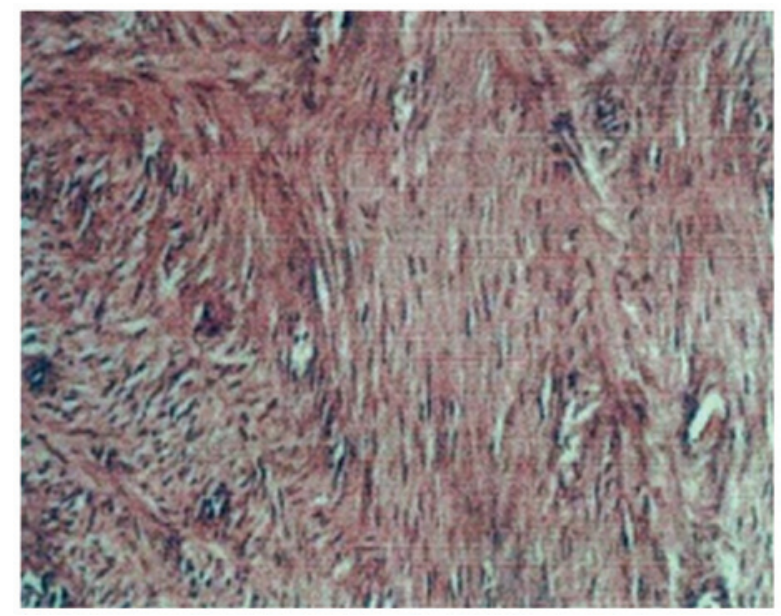

Figure 2. Postoperative pathology slide example of removed fibroid tissue.

Characteristics studied. Surgical features for the patients in both groups such as duration of operation, intra-operative amount of bleeding and postoperative recovery period were evaluated and compared. Markers of ovarian endocrine function and blood supply were measured prior to the surgeries and one month after the procedure. These included serum levels of hormones such as PRL (prolactin), E2 (estradiol), FSH (follicle stimulating hormone) and LH (luteinizing hormone), and doppler ultrasound measurements like PI (pulsatility index), RI (resistance index), Vmin (the minimal end diastolic velocity of blood flow) and Vmax (the maximal systolic velocity of blood flow). Complete healing or fibroid recurrence were monitored during the follow-up period.

Statistical analysis. The SPSS 20.0 (IBM Corp., Armonk, NY, USA) software was used for analysis. Measurement data were expressed as mean \pm standard deviation and were analyzed by the $\chi^{2}$ test. Enumeration data were analyzed using paired-samples t-test. A $\mathrm{P}<0.05$ was considered to indicate a statistically significant difference.

\section{Results}

Comparison of relevant surgical characteristics in both groups. The operation durations, amounts of bleeding and recovery periods for patients in the observation group were significantly lower than those for patients in the control group $(\mathrm{P}<0.05)$ (Table I). 
Table II. Comparisons of preoperative and postoperative ovarian function indexes for patients in the two groups (mean \pm SD).

\begin{tabular}{llcccc}
\hline Group (n, no. of cases) & \multicolumn{1}{c}{ Time } & PRL $(\mu \mathrm{g} / \mathrm{l})$ & FSH (U/l) & E2 (U/l) & LH (U/l) \\
\hline Control (n=62) & Preoperative & $9.62 \pm 1.17$ & $12.36 \pm 3.52$ & $4.16 \pm 0.27$ & $7.38 \pm 1.25$ \\
& 1-month post-surgery & $27.13 \pm 3.42^{\mathrm{a}}$ & $25.91 \pm 3.63^{\mathrm{a}}$ & $2.13 \pm 0.15^{\mathrm{a}}$ & $15.29 \pm 3.65^{\mathrm{a}}$ \\
& Preoperative & $9.45 \pm 1.18$ & $12.49 \pm 3.28$ & $4.13 \pm 0.32$ & $7.44 \pm 1.32$ \\
Observation (n=62) & 1-month post-surgery & $14.34 \pm 3.26^{\mathrm{a}, \mathrm{b}}$ & $15.82 \pm 3.64^{\mathrm{a}, \mathrm{b}}$ & $3.79 \pm 0.243^{\mathrm{a}, \mathrm{b}}$ & $12.1 \pm 2.87^{\mathrm{a}, \mathrm{b}}$
\end{tabular}

${ }^{\mathrm{a}} \mathrm{P}<0.05$, intra-group comparisons; ${ }^{\mathrm{P}} \mathrm{P}<0.05$ comparisons among groups; $\mathrm{SD}$, standard deviation; $\mathrm{PRL}$, prolactin; FSH, follicle stimulating hormone; E2, estradiol; LH, luteinizing hormone.

Table III. Comparison of preoperative and postoperative blood supply indexes via doppler ultrasound for patients in both groups $($ mean $\pm \mathrm{SD})$.

\begin{tabular}{llllll}
\hline Groups (n, no. of cases) & \multicolumn{1}{c}{ Time } & PI $(\mu \mathrm{g} / \mathrm{l})$ & RI $(\mathrm{U} / \mathrm{l})$ & $\mathrm{Vmin}(\mathrm{m} / \mathrm{sec})$ & $\mathrm{Vmax}(\mathrm{m} / \mathrm{sec})$ \\
\hline Control (n=62) & Preoperative & $1.55 \pm 0.24$ & $0.75 \pm 0.06$ & $0.18 \pm 0.25$ & $0.56 \pm 0.17$ \\
& 1-month after surgery & $2.26 \pm 0.97^{\mathrm{a}}$ & $0.94 \pm 0.03^{\mathrm{a}}$ & $0.05 \pm 0.02^{\mathrm{a}}$ & $0.13 \pm 0.07^{\mathrm{a}}$ \\
Observation (n=62) & Preoperative & $1.57 \pm 0.35$ & $0.77 \pm 0.05$ & $0.17 \pm 0.12$ & $0.54 \pm 0.16$ \\
& 1-month after surgery & $1.89 \pm 0.32^{\mathrm{a}, \mathrm{b}}$ & $0.82 \pm 0.07^{\mathrm{a}, \mathrm{b}}$ & $0.14 \pm 0.03^{\mathrm{a}, \mathrm{b}}$ & $0.42 \pm 0.02^{\mathrm{a}, \mathrm{b}}$ \\
\hline
\end{tabular}

${ }^{\mathrm{a}} \mathrm{P}<0.05$, intra-group comparisons; ${ }^{\mathrm{P}} \mathrm{P}<0.05$, comparisons among groups; PI, pulsatility index; RI, resistance index; Vmin, the minimal end diastolic velocity of blood flow; Vmax, the maximal systolic velocity of blood flow; SD, standard deviation.

Table IV. Comparison of healing conditions of postoperative abdominal muscular layers at different time points for patients in both groups [percentage (rate)].

\begin{tabular}{lcccc}
\hline Groups & $\begin{array}{c}1 \text { month } \\
\text { after operation }\end{array}$ & $\begin{array}{c}4 \text { months } \\
\text { after operation }\end{array}$ & $\begin{array}{c}8 \text { months } \\
\text { after operation } \\
\text { after operation }\end{array}$ \\
\hline Control & $48.4(30 / 62)$ & $62.9(39 / 62)$ & $88.7(55 / 62)$ & $96.8(60 / 62)$ \\
Observation & $61.3(38 / 62)$ & $77.4(48 / 62)$ & $100(62 / 62)$ & $100(62 / 62)$ \\
$\chi^{2}$ & 13.621 & 14.075 & $<.338$ & 15.564 \\
P-value & $<0.01$ & $<0.01$ & $<0.01$ & $<0.01$ \\
\hline
\end{tabular}

Comparison of preoperative and postoperative ovarian function indexes in both groups. Compared with preoperative conditions, the levels of ovarian function markers PRL, FSH, E2 and LH of the patients in both groups were significantly lower one month after the surgery. But the levels of the patients in the observation group were still significantly higher than those of the patients in the control group $(\mathrm{P}<0.05)$ (Table II).

Comparisons of preoperative and postoperative ovarian blood supply changes for both groups as evidenced by Doppler ultrasound. Compared with preoperative conditions, the levels of PI, RI, Vmin and Vmax were significantly lowered in both groups. But the levels of the patients in the observation group were significantly higher than those in the control group evidencing a lower impact of the surgical procedure on the resulting ovarian blood flow $(\mathrm{P}<0.05)$ (Table III).

Comparison of healing conditions of postoperative abdominal muscular layers. At all different time points examined (1, 4, 8, and 12 months after surgery) the complete healing rates of the abdominal muscular layers of the patients in the observation group were higher than those of the patients in the control group $(\mathrm{P}<0.01)$ (Table IV).

Comparisons of postoperative recurrence rates for both groups. Postoperative follow-up visits were carried out for the patients in both groups. Median periods of postoperative follow-up for the patients in the control and observation groups were respectively 13 and 14 (5-24 months). The ultrasound fibroid images of the patients in both groups disappeared instantly after the operations (Fig. 3).

At the end of the 24 months of the follow-up period, the recurrence rate in observation group was $4.8 \%$ and recurrence rate in control group was $3.2 \%$; there were no significant differences in the comparison of the groups $(\mathrm{P}>0.05)$. From the first postoperative day to the last follow-up visit on January 1, 2017, monitoring was made regularly; the sizes of recurrent fibroids were recorded and averaged $3.5 \times 2.4 \times 3.2 \mathrm{~cm}$ (Fig. 4). 


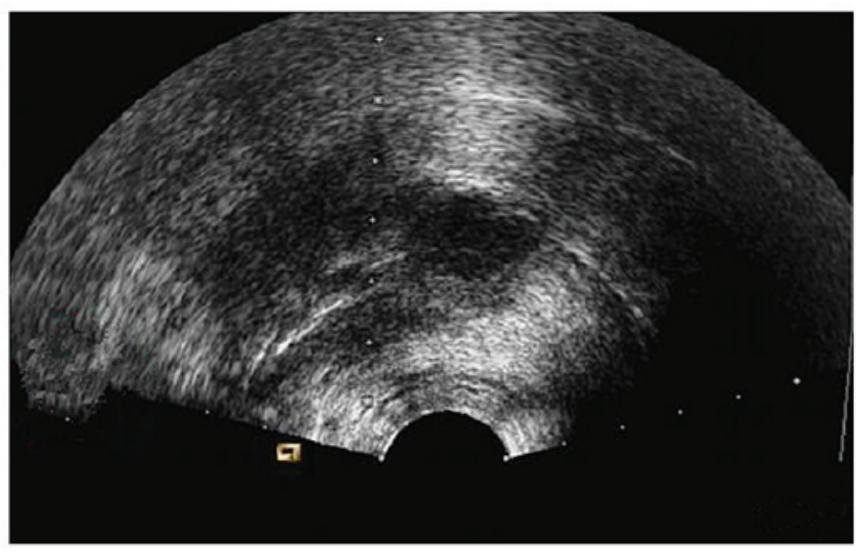

Figure 3. Post-operative ultrasound view showing no fibroids after the operation.

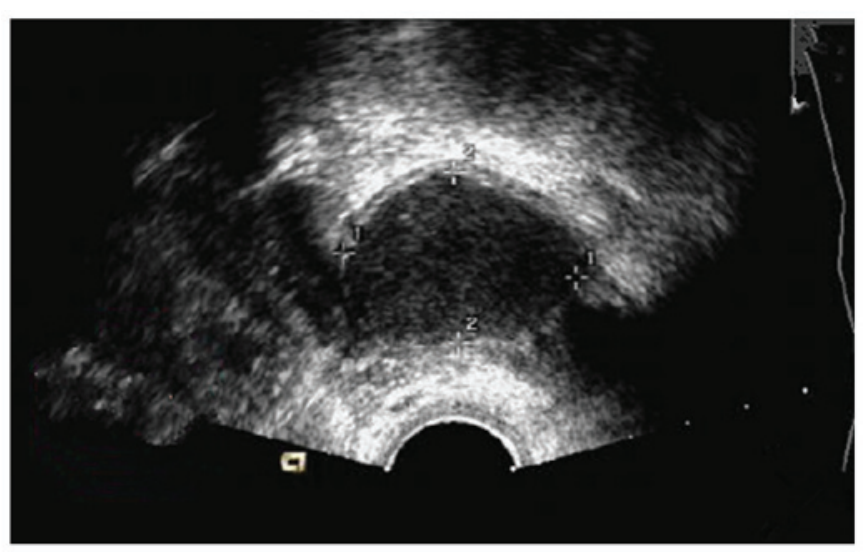

Figure 4. Postoperative ultrasound image during a follow-up visit showing average size of recurring fibroids.

\section{Discussion}

Uterine fibroids are common gynecological benign tumors, which can cause menostaxis, a swollen lower abdomen, menorrhagia and other symptoms and may lead to secondary anemia (5-7) due to excessive vaginal blood loss in severe cases. Clinical treatment for uterine fibroids relies mostly on surgical procedures and the resulting adverse effects of the different operating methods on the ovarian blood supply and endocrine function continue to be key topics of clinical discussions (8-10).

In recent years, the former abdominal hysterectomy has gradually been replaced by laparoscopy. Compared with traditional abdominal hysterectomy, laparoscopic hysterectomy has such advantages as shorter duration of operation, small trauma and rapid postoperative recovery and it can effectively diminish wound infection risks and does not cause as much pain to patients $(11,12)$. In addition, laparoscopic hysterectomy can be used to inspect pelvic and abdominal organs by means of the laparoscope, directly showing the condition of fallopian tubes and ovaries and it can be used to diagnose accompanying diseases of the pelvic cavity such as endometriosis and it can separate abdominal and pelvic adhesions present (13-16). Additionally, the traditional abdominal hysterectomy causes larger body surface scars and trauma, subjects patients to a slower postoperative recovery and is less well tolerated by most patients. Nevertheless, operation safety during laparoscopic hysterectomy not only depends on laparoscopic technology but also on the accumulated experience of the surgeons and requires close monitoring for changes on the patients' condition and postoperative follow-up visits. If vaginal bleeding or other abnormal circumstances are encountered during the postoperative recovery period, effective treatment measures need to be taken immediately; and patients need to be advised to avoid sexual intercourse for an agreed period of time after the procedure (16-19). The results of this study showed the usual advantages of the laparocopic procedure over the abdominal open hysterectomy, but the evidence also seemed to prove that the adverse impact of the procedure on the ovarian blood flow and function was significantly diminished with the laparoscopic surgery as has been seen by others (20). The findings that the abdominal muscular layer of the patients in the observation group healed completely significantly and faster than in the control group and the low recurrence rate of fibroids of $4.8 \%$ in the laparoscopy group point to the clinical effectiveness and feasibility of the procedure applied to the patients with uterine fibroids. This study has limitations such as the lack of discussion of postoperative complications and the short follow up periods, which should be addressed in future larger studies.

\section{References}

1. Yuan H, Wang C, Wang D and Wang Y: Comparing the effect of laparoscopic supracervical and total hysterectomy for uterine fibroids on ovarian reserve by assessing serum anti-mullerian hormone levels: A prospective cohort study. J Minim Invasive Gynecol 22: 637-641, 2015.

2. Istre $\mathrm{O}$ and Springborg H: How to avoid laparotomy doing laparoscopic hysterectomy. J Minim Invasive Gynecol 22: S221, 2015.

3. Matsuguchi K, Takahashi S, Miyagawa M, Uesugi Y, Kamura T and Hatase T: Outcomes of single port laparoscopically assisted vaginal hysterectomy. Jpn J Gynecol Obstet Endosc 30: 396-399, 2015.

4. Dixit N, Jesner O and Modarres M: Endoscopic treatment and power morcellation of uterine fibroids. Curr Obstet Gynecol Rep 5: 94-105, 2016.

5. Wang P, Wang XP, Li YY, Jin BY, Xia D, Wang S and Pan H: Hydronephrosis due to ureteral endometriosis in women of reproductive age. Int J Clin Exp Med 8: 1059-1065, 2015.

6. Hinchcliff EM and Cohen SL: Laparoscopic hysterectomy for uterine fibroids: Is it safe? Clin Obstet Gynecol 59: 66-72, 2016.

7. Cohen SL, Hariton E, Afshar Y and Siedhoff MT: Updates in uterine fibroid tissue extraction. Curr Opin Obstet Gynecol 28: 277-282, 2016.

8. Angioni S, Pontis A,Pisanu A, Mereu L and Roman H: Single-port access subtotal laparoscopic hysterectomy: A prospective case-control study. J Minim Invasive Gynecol 22: 807-812, 2015.

9. Puchar A, Feyeux C, Luton D and Koskas M: Therapeutic management of uterine fibroid tumors. Minerva Ginecol 68: 466-476, 2016

10. Odejinmi F, Maclaran K and Agarwal N: Laparoscopic treatment of uterine fibroids: A comparison of peri-operative outcomes in laparoscopic hysterectomy and myomectomy. Arch Gynecol Obstet 291: 579-584, 2015.

11. Thyagaraju C and Modi R: Feasibility of total laparoscopic hysterectomy as a day care procedure. Int $\mathrm{J}$ Reprod Contracept Obstet Gynecol 3: 735-741, 2014.

12. Ghezzi F, Cromi A, Bergamini V, Uccella S, Beretta P, Franchi M and Bolis P: Laparoscopic-assisted vaginal hysterectomy versus total laparoscopic hysterectomy for the management of endometrial cancer: A randomized clinical trial. J Minim Invasive Gynecol 13: 114-120, 2006.

13. Cook H, Ezzati M, Segars JH and McCarthy K: The impact of uterine leiomyomas on reproductive outcomes. Minerva Ginecol 62: 225-236, 2010. 
14. Laughlin SK, Baird DD, Savitz DA, Herring AH and Hartmann KE: Prevalence of uterine leiomyomas in the first trimester of pregnancy: An ultrasound-screening study. Obstet Gynecol 113: 630-635, 2009.

15. Ruan JY, Chen HQ, Gong YH, Shi G and Wang H: Laparoscopic subtotal hysterectomy due to giant uterine fibroids: A case report. Clin Exp Obstet Gynecol 43: 134-136, 2016.

16. Kalir T, Goldstein M, Dottino P, Brodman M, Gordon R, Deligdisch L, Wu H and Gil J: Morphometric and electron-microscopic analyses of the effects of gonadotropin-releasing hormone agonists on uterine leiomyomas. Arch Pathol Lab Med 122: 442-446, 1998.

17. Hur HC, King LP, Klebanoff MJ, Hur C and Ricciotti HA: Fibroid morcellation: A shared clinical decision tool for mode of hysterectomy. Eur J Obstet Gynecol Reprod Biol 195: 122-127, 2015.
18. Beinfeld MT, Bosch JL and Gazelle GS: Hospital costs of uterine artery embolization and hysterectomy for uterine fibroid tumors. Acad Radiol 9: 1300-1304, 2002.

19. Kong CY, Meng L, Omer ZB, Swan JS, Srouji S, Gazelle GS and Fennessy FM: MRI-guided focused ultrasound surgery for uterine fibroid treatment: A cost-effectiveness analysis. AJR Am J Roentgenol 203: 361-371, 2014

20. Pritts EA, Vanness DJ, Berek JS, Parker W, Feinberg R, Feinberg J and Olive DL: The prevalence of occult leiomyosarcoma at surgery for presumed uterine fibroids: A meta-analysis. Gynecol Surg 12: 165-177, 2015. 